\title{
Rectal Neuroendocrine Tumor
}

\author{
National Cancer Institute
}

\section{Source}

National Cancer Institute. Rectal Neuroendocrine Tumor. NCI Thesaurus. Code C135213.

A well differentiated, low or intermediate grade tumor with neuroendocrine

differentiation that arises from the rectum. 